\title{
Desenvolvimento profissional e formação contínua de professores: uma análise do contexto da educação em Angola
}

\section{Professional development and teachers continuing education: an analysis of the context of education in Angola}

\author{
Ariete de Fátima Paiva Cameira ${ }^{1}$, José María Romero Rodríguez² ${ }^{2}$ Gerardo Gómez García ${ }^{3}$ \\ ${ }^{1}$ Escola 22 de Novembro de Luanda, Angola (ariecameira@hotmail.com) \\ ${ }^{2}$ Universidad de Granada, España (romejo@ugr.es) \\ ${ }^{3}$ Universidad de Granada, España (gerardo_acci@hotmail.com)
}

\section{RESUMO:}

A análise das ações de formação contínua de professores é uma questão relevante para conhecer o nível de treinamento e desenvolvimento profissional dos professores nas escolas. Também nos permite obter dados sobre a atualização de habilidades profissionais que são fundamentais para o exercício de uma profissão em constante mudança. Por conseguinte, este artigo visa analisar a formação contínua e o desenvolvimento profissional de professores em escolas privadas em Luanda, Angola. Assim, a metodologia de pesquisa em que este trabalho se baseia é tanto quantitativa como qualitativa. Desta forma, a entrevista e o questionário foram utilizados como instrumentos para coletar informações. Os principais resultados são que não há um programa específico de treinamento contínuo em instituições privadas, observando a ausência de balanços periódicos para analisar o nível de desenvolvimento profissional dos professores e outros profissionais envolvidos. Em conclusão, os professores em Angola estão motivados para continuar a formação, mas existem certas barreiras institucionais que não favorecem a formação contínua e o desenvolvimento profissional.

PALAVRAS CHAVE: DESENVOLVIMENTO PROFISSIONAL, FORMAÇÃO CONTÍNUA, COMPETÊNCIAS TREINAMENTO.

\begin{abstract}
:
The analysis of the actions of continuous training of teachers is a relevant question to know the level of training and professional development of teachers in schools. It also allows us to obtain data on updating professional skills that are fundamental to the exercise of an ever-changing profession.Therefore, this article aims to analyze the continuing education and professional development of teachers in private schools in Luanda, Angola.Thus, the research methodology on which this work is based is both quantitative and qualitative.In this way, the interview and the questionnaire were used as instruments to collect information. The main results are that there is no specific program of continuous training in private institutions, noting the absence of periodic balance sheets to analyze the level of professional development of teachers and other professionals involved. In conclusion, teachers in Angola are motivated to continue training, but there are certain institutional barriers that do not favor continuous training and professional development.
\end{abstract}

KEYWORDS:

PROFESSIONAL DEVELOPMENT, CONTINUOUS TRAINING, TRAINING COMPETENCES. 


\section{INTRODUÇÃO}

O mundo não para, e as necessidades transformamse e desenvolvem-se a medida que mudam as pessoas, com novas ideias e capacidades de pensar diferente de modo que possam aplicar novas fórmulas para mudar a educação. Não existem mudanças na educação, se não mudarmos as nossas práticas de ensino, as nossas formas de organização por meio de formação contínua (González, \& Cutanda, 2017). Verificamos que os fazedores da educação estão preocupadas com o aperfeiçoamento de conhecimentos por meio de formação contínua, mas é preciso fazer muito mais pela educação no nosso País.

A melhoria da qualidade de ensino passa por várias etapas como a construção de novas estruturas escolares, o equipamento que as escolas devem estar munidas de acordo ao seu nível de ensino, a monitorização destas instalações e o principal os quadros capacitados para enfrentar as demandas sociais (Rodríguez, \& Hinojo, 2017).

Ao ser atribuída ao professor a responsabilidade de ensinar, orientar e transformar as mentes, cabe aos responsáveis da educação junto das direcções das escolas criar políticas de formação para que de facto se possa munir os mesmos de competências necessárias para o desempenho eficaz de sua actividade enquanto educadores.

Sendo as competências de grande importância para a profissionalização da docência (Joana, Sola, \& Aznar, 2017) é necessário que a formação contínua seja uma realidade no nosso País de acordo as políticas que devem ser criadas, que devem abarcar todas as zonas rurais (Raso, Sola \& Hinojo, 2017) e urbanas de um estado, que as direcções das escolas tenham profissionais capacitados, com o objectivo de criar parcerias, que podemos começar pelas zonas de influências pedagógicas criadas a nível dos municípios de modo a melhorar o nosso trabalho.

Um dos grandes males das instituições de ensino é não termos no topo pessoas capacitadas para exercerem o real papel de pedagogos transformadores de consciências, e capazes de mudar as práticas de ensino dos seus professores.

Contudo, as escolas como palco com vários actores onde o papel fundamental é ensinar e educar de modo a mudar qualquer sociedade, precisa de ter actores capazes de mudar a educação e para tal é necessário que as direcções transformem estes lugares (Hinojo, Cáceres, \& Raso, 2013; Moisés, Aznar, \& Agreda, 2017) em lugares onde todos os dias haja formação a nível pessoal, afectivo e profissional.

\section{METODOLOGIA}

Para o nosso trabalho utilizamos a metodologia descritiva, onde iremos aplicar o método misto e utilizaremos simultaneamente a abordagem qualitativa e a quantitativa. A investigação descritiva, como o próprio nome sugere, tem por objectivo descrever um determinado fenómeno (Fox, 1987). Por outro lado, como afirma Bisquerra (1989, p. 65), a investigação descritiva "pode utilizar metodologia qualitativa ou quantitativa". Segundo o mesmo autor o propósito da observação é provar profundamente e analisar intensamente os fenómenos diversos que constituem o ciclo vital de uma unidade, com visão para estabelecer generalizações acerca da mas ampla população a que pertence a unidade.

Este estudo se desenvolverá numa perspectiva investigativa centrada na compreensão do objecto estudado. No papel de investigadores formulamos a pergunta inicial e os materiais metodológicos a serem utilizados de forma a prosseguir com a pesquisa. A opção pelos locais de estudo, como já foi justificado, prendem-se com o facto de exercermos funções de directora de uma das Escola seleccionadas, o que facilitará o acesso ao campo empírico. Neste contexto, optou-se por realizar um estudo em quatrocentas instituições de ensino particular existentes na província de Luanda (Angola). Esta opção resultou do facto de querermos efectuar o nosso estudo em instituições privadas de modo a compreender como a nossa problemática aí se desenvolve, não queremos por isso seleccionar nenhuma instituição em particular mas antes obter uma visão global do panorama da formação contínua nos estabelecimentos de ensino particular da província de Luanda.

Por outro lado, como não há estudos sobre esta temática em Angola e sendo a província de Luanda a maior e com mais densidade populacional um estudo global poderá alargar as perspectivas sobre a formação contínua e sobre as modalidades e formas de acompanhamento promovidas ao nível institucional. Com uma amostra mais alargada poderemos identificar com maior profundidade as necessidades, interesses, expectativas e perspectivas da formação contínua. Estes propósitos prendem-se com necessidades e vontade de continuar a aumentar o nível de conhecimento em termos metodológicos e não só com o intuito de construir e delimitar a problemática em foco. Assim, o passo inicial deste estudo será orientado pelo referencial teórico recolhido em sua grande parte através da revisão da literatura e do levantamento bibliográfico sobre as 
considerações que se prendem com a temática do estudo.

Desta forma, a construção do referencial teórico permitirá fundamentar e orientar a construção dos instrumentos metodológicos bem como em seleccionar os procedimentos e técnicas de análise dos dados numa pesquisa descritiva em que se estabelecerá a complementaridade com a metodologia qualitativa e quantitativa, uma vez que são acordes para analisar o formação (García, \& Aznar, 2017). Existem muitos autores que não aceitam a dicotomia na investigação qualitativa/quantitativa e sustentam a existência de um contínuo entre esses dois tipos de investigação (Lessard-Hébert et al., 2005). Existem também autores, como por exemplo Yin (2005) e Flick (2004), que salientam a relevância de utilizar, em alguns métodos de investigação, simultaneamente dados qualitativos e quantitativos. A utilização de dados qualitativos e quantitativos, na mesma investigação, vai no sentido de olhar para estas metodologias como complementares e não como opostas ou rivais.

Em suma, esta maneira de pensar orienta a nossa abordagem, enquanto estratégia de investigação, aliás parece-nos mais interessante para a nossa investigação, na medida em que nos permite fazer uma utilização complementar de dados de natureza qualitativa e quantitativa numa lógica de construção e interpretação de conhecimento com vista à obtenção de uma visão mais global e aprofundada da temática da formação contínua em contexto de desenvolvimento profissional dos docentes do ensino privado.

\subsection{Objectivos}

Dada a importância da questão da educação continuada dos professores, nosso estudo procurará descobrir em que medida o quadro de treinamento nas instituições em estudo pode ser útil no desenvolvimento de habilidades profissionais de nossos professores (Gracia, 2017). Assim, com este estudo pretendemos atingir como objetivo geral: contribuir para o aprimoramento e melhoria da formação contínua e a qualificação dos professores da escola primária.

Enquanto como objetivos específicos:

1. Identificar as perspectivas que os professores primários e do $1^{\circ}$ Ciclo têm sobre a formação contínua em geral.

2. Identificar o modelo e os tipos de formação contínua que os professores têm frequentado.

3. Identificar as necessidades de formação contínua dos professores em estudo.
4. Conhecer as propostas de formação contínua e os planos de formação promovidos pelas instituições seleccionadas e analisar de que modo a formação contínua 'oferecida' vai de encontro aos interesses, expectativas e necessidades dos profesores.

5. Compreender o modo como os professores primários e do $1^{\circ}$ ciclo percepcionam o seu percurso de formação e de desenvolvimento profissional.

6. Analisar os efeitos da formação contínua efectivamente frequentada nas representações e práticas dos profesores.

7. Compreender as implicações da formação contínua frequentada ao nível do desenvolvimento profissional dos professores e da(s) sua(s) identidade(s) profissional(ais).

8. Promover a formação em serviço dos jovens professores a leccionar nos colégios seleccionados para o estudo.

9. Analisar e interpretar o acompanhamento pedagógico dos professores das instituições seleccionadas.

10. Conhecer a importância dada pelas direcções dos Colégios à formação contínua dos seus professores.

11. Aferir o tipo e os critérios de avaliação da formação promovidos por estas instituições.

\subsection{População e amostra}

População é o conjunto de pessoas de uma determinada unidade ou instituição de ensino que serão alvo da nossa investigação. Neste trabalho a nossa população servirá na totalidade para a nossa pesquisa já que utilizaremos a metodologia descritiva.

Para a elaboração deste trabalho teremos como universo institucional 400 colégios da província de Luanda. Desse universo seleccionaremos através de amostra aleatória, 5 elementos da direcção (directores e sub-directores pedagógicos) e 215 professores extraídos também aleatoriamento do universo de 1090 professores desses estabelecimentos de ensino. Só podemos aceder a 500 professores que estavam disponíveis nas instituições. Estas amostras parecem-nos significativas pois representam $43 \%$ do total da população o que nos permitirá já extrair ilações globais no sentido da compreensão e descrição do fenómeno em estudo.

\subsection{Instrumentos de investigação}

Para melhor definirmos o nosso trabalho, recorreremos a diferentes instrumentos de recolha de dados que permitirão uma análise quantitativa e 
qualitativa. Para análise quantitativa foi usado inquérito por Questionário. Em a realização do nosso trabalho utilizaremos o questionário para a recolha de dados referentes a formação contínua de professores a 215 professores dos colégios em estudo, mas começaremos por fazer a validação do instrumento através de um pré-teste para comprovar se as questões vão de encontro aos nossos objectivos.

O nosso questionário foi elaborado com base na revisão da literatura e nos objectivos por nós definidos. Este questionário está dividido em 4 partes. $\mathrm{Na} 1^{\text {a }}$ parte encontram-se as questões referentes aos dados sociodemográficos que permitirão caracterizar a amostra em estudo. As restantes secções do questionário incidem sobre questões alusivas à temática em estudo. $\mathrm{Na} 2^{\mathrm{a}}$ Secção encontra-se um conjunto de questões relativas à tipologia, frequência, motivos $\mathrm{e}$ modalidades da formação contínua frequentada pela amostra nos últimos 5 anos. $\mathrm{Na} 3^{\text {a }}$ secção encontrase um conjunto de questões relativas às repercussões da formação frequentada e por fim, na última parte do questionário encontra-se um conjunto de questões referentes à organização, qualidade e validade da formação contínua. Todas as questões das três partes principais do questionário são questões fechadas de escolha múltipla com recurso a uma escala de Lickert. $\mathrm{Na} 2^{\mathrm{a}}$ secção relativamente ao grau de importância atribuída à formação contínua optámos por uma escala com 4 itens, a saber, MI = muito importante; I = Importante; $\mathrm{PI}=$ pouco importante; $\mathrm{NI}=$ nada importante. Nas restantes secções, a escala é utilizada com 5 itens numerados de 1 a 5 com o seguinte critério: 1. Discordo totalmente; 2. Discordo; 3. Não concordo nem discordo; 4. Concordo; 5. Concordo Totalmente.

Em vez disso para análise qualitativa foi usado inquérito por Entrevista, segundo Martins, \& Lintz (2000, p. 54) "a entrevista é uma técnica que requer muita habilidade, sendo o seu objectivo básico entender o significado que os entrevistados atribuem a questões e situações em contextos que não foram estruturados anteriormente com base nas suposições e conjecturas do pesquisador". Por outro lado, do ponto de vista de Marconi, \& Lakatos (2010, p. 80), "a entrevista é um encontro entre duas pessoas, a fim de que uma delas obtenha informações a respeito de determinado assunto, mediante uma conversação de natureza profissional. É um procedimento utilizado na investigação social, para a colecta de dados ou para ajudar no diagnóstico ou no tratamento de um problema social".
Para a recolha de informação dos elementos directivos das instituições utilizaremos este instrumento de pesquisa, que permitirá compreender que representações têm os elementos das direcções sobre a formação contínua, que tipo de acompanhamento e promoção fazem da avaliação contínua e como percepcionam o seu impacto. A entrevista será semi-estrutrada e será efectuada de acordo com a disponibilidade manifestada pelos entrevistados. As entrevistas serão gravadas, transcritas e posteriormente será efectuada a sua análise de conteúdo.

A entrevista foi elaborada partindo da revisão da literatura e da adaptação de instrumentos semelhantes que encontramos em outros estudos efectuados em temáticas semelhantes à nossa. Assim, foram definidos previamente os blocos e os objectivos para o guião. Em seguida efectuaram-se as questões e após o guião da entrevista completo elaborou-se a grelha de análise de conteúdo com as categorias, sub-categorias e indicadores que permitirão efectuar a análise de conteúdo aos dados obtidos com as entrevistas. O guião e a grelha de análise de conteúdo encontram-se em anexo.

Assim pois, o primeiro questionário é de grande utilidade para que os aplica permitindo deste modo colher informações mais profundas e precisas; contudo, apresentam alguns inconvenientes, uma vez que dificultam as respostas aos próprios respondentes que deverão redigi-las e igualmente complexas para o investigador que tem de interpretar e tratar estatisticamente, tornando-se mais trabalhoso pela dificuldade da análise ser difícil, complexa, cansativa e demorada.

Recorrer ao segundo tipo de questionário é mais vantajoso para o investigador de modo que é mais fácil, permitindo ao investigador maior conhecimento das variáveis obtendo deste modo informações qualitativas sobre elas.

\section{RESULTADOS E DISCUSSÃO}

O pesquisa teve 215 inqueridos onde obtivemos os seguintes resultados. Sobre as acções de formação frequentadas verificamos que a maior frequência 54 com a percentagem de $(25,1 \%)$ recai para módulos de formação que são preparados pelas instituições onde trabalham e salientam a percentagem dos inqueridos que não sabem e os que não contestam de $(8,8 \%)$ conforme mostra os gráficos (figura $1 \mathrm{e}$ tabela 1). 
Tabela 1. Acções de formação.

\begin{tabular}{|c|c|c|c|c|}
\hline & $\begin{array}{c}\text { Frequêr } \\
\mathrm{a}\end{array}$ & $\begin{array}{c}\text { centa } \\
\mathrm{m}\end{array}$ & $\begin{array}{l}\text { Percentage } \\
\text { m válido }\end{array}$ & $\begin{array}{c}\text { Percentage } \\
\text { m } \\
\text { acumulado }\end{array}$ \\
\hline $\mathrm{NS} / \mathrm{NC}$ & 19 & 8,8 & 8,8 & 8,8 \\
\hline $\begin{array}{l}\text { Curso de } \\
\text { formação }\end{array}$ & 27 & 12,6 & 12,6 & 21,4 \\
\hline $\begin{array}{l}\text { Módulo de } \\
\text { formação }\end{array}$ & 54 & 25,1 & 25,1 & 46,5 \\
\hline $\begin{array}{l}\text { Círculo de } \\
\text { estudos }\end{array}$ & 44 & 20,5 & 20,5 & 67,0 \\
\hline $\begin{array}{l}\text { Seminários } \\
\text { de } \\
\text { refrescament } \\
\text { o }\end{array}$ & 40 & 18,6 & 18,6 & 85,6 \\
\hline $\begin{array}{l}\text { Oficina de } \\
\text { formação }\end{array}$ & 31 & 14,4 & 14,4 & 100,0 \\
\hline Total & 215 & 100,0 & 100,0 & \\
\hline
\end{tabular}

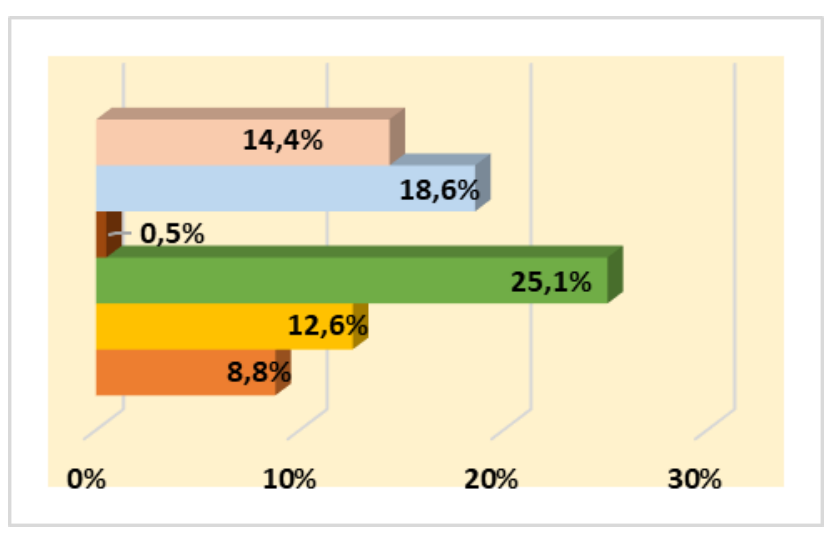

Figura 1. Acções de formação.

A informação recolhida mostra que a grande maioria é de 136 com uma percentagem valida de $63,3 \%$ do total dos inqueridos. Podemos verificar de acordo com as tabela 2 e gráfico (figura) uma grande preocupação para a frequência as formações que são preparadas nestas instituições e fora delas.

Tabela 2. Frequência das acções.

\begin{tabular}{|c|c|c|c|c|}
\hline & Frequência & $\begin{array}{c}\text { Percentage } \\
\mathrm{m}\end{array}$ & $\begin{array}{l}\text { Percentagem } \\
\text { válido }\end{array}$ & $\begin{array}{c}\text { Percentagem } \\
\text { acumulado }\end{array}$ \\
\hline 0 & 34 & 11,2 & 11,2 & 11,2 \\
\hline 1 & 136 & 63,3 & 63,3 & 74,4 \\
\hline 2 & 39 & 18,1 & 18,1 & 92,6 \\
\hline 3 & 8 & 3,7 & 3,7 & 96,3 \\
\hline 4 & 4 & 1,9 & 1,9 & 98,1 \\
\hline 5 & 4 & 1,9 & 1,9 & 100,0 \\
\hline Total & 215 & 100,0 & 100,0 & \\
\hline
\end{tabular}

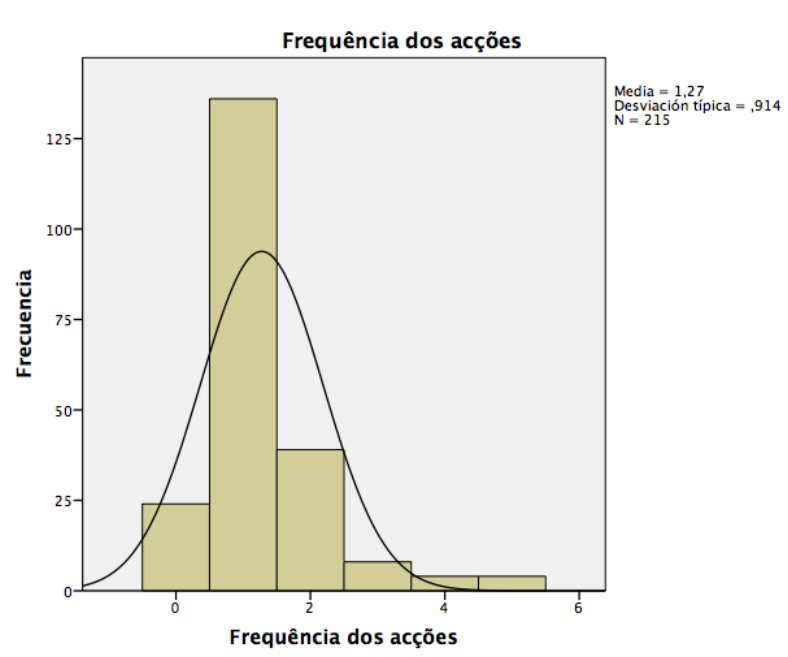

Figura 2. Frequência das acções.

Com relação as formações que frequentaram nos últimos cinco anos verificamos uma frequência de 103 correspondente a uma percentagem de $47,9 \%$ de acordo ao figura 3 .

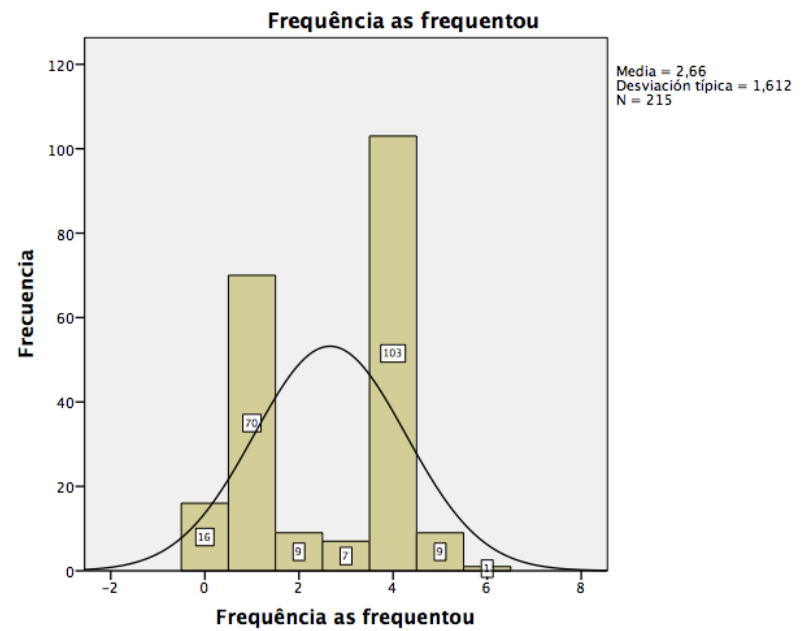

Figura 3. Frequência as frequentou.

Observando os resultados referentes a este ponto, a grande maioria das instituições prepara formações para melhorar a qualidade dos seus docentes. Verificamos uma frequência de $1,4 \%$ professores que não sabe ou não contesta, $64,7 \%$ afirmam que fazem as formações nas escolas onde leccionam $14,9 \%$ afirmam que as formações programadas pelo ministério da educação, e 19,1\% afirmam que fazem as formações durante a sua formação acadêmica na universidade (figura 4). Aspecto que é fundamental nos programas de treinamento pedagógico (Rodríguez, \& Hinojo, 2017). 


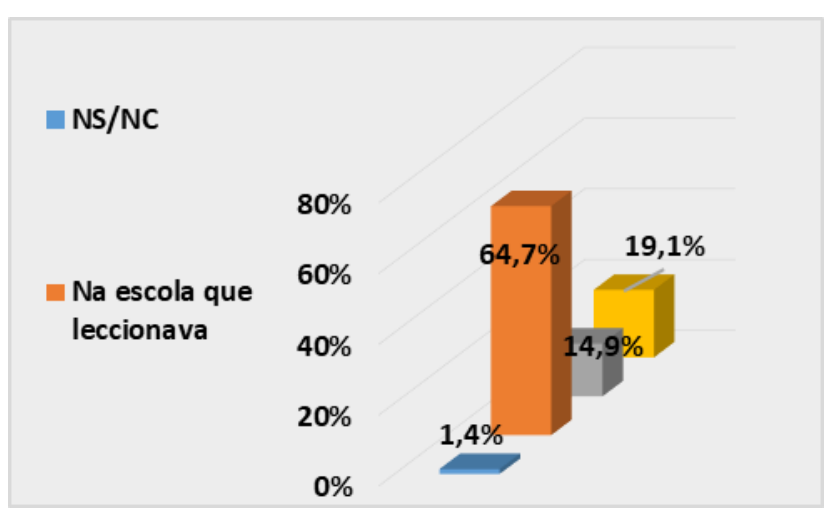

Figura 4. Instituições que prepara formações.

Pretendeu-se saber as razões/motivos da escolha do local para fazer formação, utilizando, para isso, uma pregunta de escolha múltipla. Destaca-se facilmente o item que indica as razões da escola atingindo uma percentagem de $70,2 \%$ para as temáticas que são abordadas nas formações como ponto fundamental seguida do cumprimento das funções docentes com $60,9 \%$ e com item com menos percentagem $33 \%$ obrigatoriedade por parte da escola (figura 5).

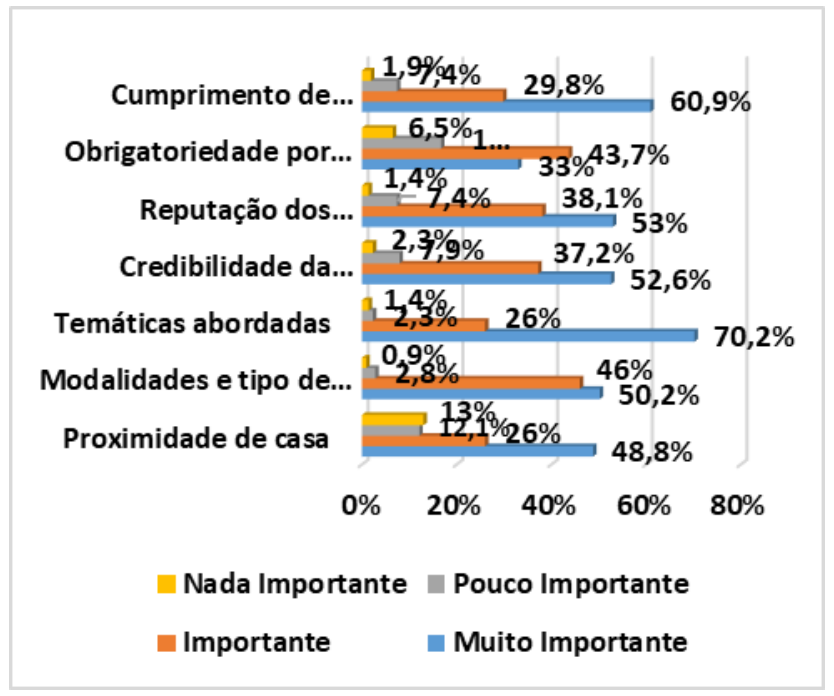

Figura 5. Razões/motivos da escolha do local para fazer a formação.

Este conjunto de variáveis procura analisar os motivos que os levaram a frequentar a formação, identificando assim o grau de importância que tem para os professores as formações por eles frequentadas. Analisando o gráfico descritiva podemos observar que uma media de $86,0 \%$ acham que essas formações são muito importantes para actualização de seus conhecimentos e ninguém afirma que é nada importante esse tipo de formação (figura 6). Esses resultados coincidem com Capistrán (2018) onde destaca-se a importância da formação contínua.

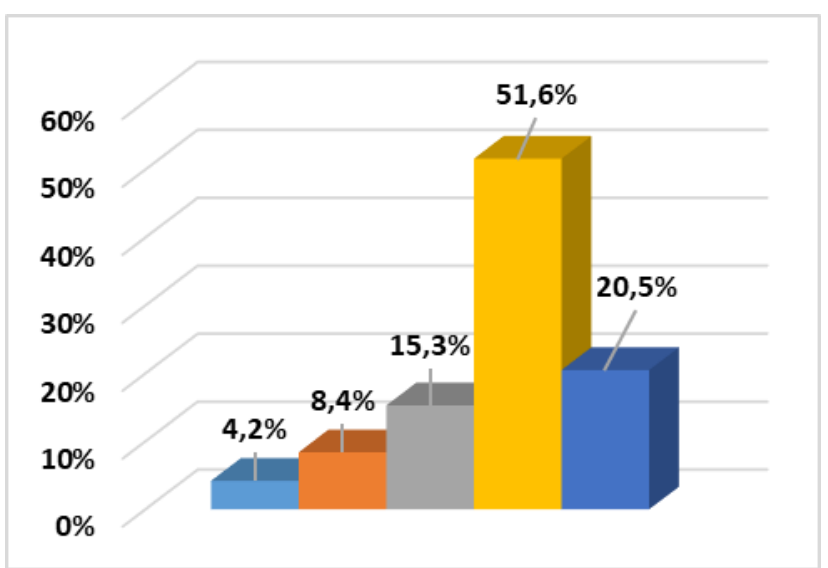

Figura 6. Foram ao encontro dos meus interesses pessoais.

A maior parte dos inqueridos concorda que as formações permitiram obter conhecimentos de áreas que não estão directamente relacionadas com a sua área específica.

\section{CONCLUSÕES}

A problemática da formação contínua nas instituições de ensino especificamente nos colégios privados de Lunda/Angola, esta directamente relacionada com a preparação dos professores que exercerem a actividade de ensinar com responsabilidade e dedicação, de modo que possa existir maior rendimento escolar e melhoria da qualidade do ensino. É um tema que deve fazer parte da planificação das actividades de uma escola pois não existem escolas em desenvolvimento se não houver investimento na formação dos quadros. Deste modo, em termos gerais podemos aferir que as conclusões mais globais:

- Os sub-directres das instituições privadas tem pouco tempo de trabalho nas instituições;

- Que os professores das instituições querem ter sub-directores mais competentes e inovadores;

- Os directores conhecem o trabalho que devem exercer nas direcções mas o problema e terem mais de um emprego impossibilita-os em dar o máximo para que o trabalho seja de qualidade;

- Que os professores estão interessados que seus alunos aprendam;

- Os donos das instituições atrapalham o trabalho que deve ser feito pelos sub-directores tirando-lhes o mérito;

- $50 \%$ dos sub-directores não são formados na área da educação, o que acaba prejudicando o trabalho pois muitos acabam aprendendo a exercer as suas actividades com os professores pois são colocados por conveniência ou por anos de serviço na educação; 
- Os sub-directores utilizam as suas experiências para passarem para os professores que com eles trabalham;

- Que em Angola a formação inicial para professores tem equivalência à 12 classe do ensino médio;

- As direcções dos colégios têm dificuldade em verificar qual altura certa para superar os seus professores;

- As direcções incentivam o trabalho colaborativo apesar da resistência;

- Que existem formações feitas nas instituições mas não devem ser consideradas de formações contínuas;

- As direcções promovem actividade para que haja formação nas instituições mais muito deficientes pois são feitas por profissionais com pouca experiência e capacidade inovadora.

Por outro lado, de acordo com cada um dos objectivos específicos do trabalho, apresentamos as conclusões mais concretas correspondentes a cada um deles.

Identificar as perspectivas que os professores primários e do $1^{\circ}$ Ciclo têm sobre a formação contínua em geral: verificamos que os professores primários querem que sejam dados temas do seu interesse, que os temas também sejam sugeridos por eles.

Identificar o modelo e os tipos de formação contínua que os professores têm frequentado: os professores frequentam mais módulos de formação centrada nas metodologias de ensino. Não existe um modelo de formação contínua.

Identificar as necessidades de formação contínua dos professores em estudo: verifica-se necessidade de formação em várias temáticas éticas e deontologia profissional, introdução as novas tecnologia de comunicação e informação, as novas estratégias de ensino para o século XXI, como identificar as crianças com dificuldades de aprendizagem.

Necessidade de formação específica nas diferentes áreas de ensino tais como Língua Portuguesa, matemática, estudo do meio, biologia, geografia, história, matemática, física, química.

Conhecer as propostas de formação contínua e os planos de formação promovidos pelas instituições seleccionadas e analisar de que modo a formação contínua 'oferecida' vai de encontro aos interesses, expectativas e necessidades dos professores: as instituições privadas planificam seminários de refrescamento para os professores e troca de experiências dentro das instituições. A maior parte das formações são organizadas pela ANEP. As formações dadas muitas vezes não vão de encontro as espectativas e necessidades dos professores mas eles as assistem de acordo aos temas sugeridos pelos formadores. Não existe nas instituições de ensino privado um plano de formação para os professores e outros elementos do processo de ensino aprendizagem.

Compreender o modo como os professores primários e do $1^{\circ}$ ciclo percepcionam o seu percurso de formação e de desenvolvimento profissional: os professores não verificam grande preocupação das instituições para o seu desenvolvimento profissional. Não se estabelecem balanços periódicos pela analisar o nível de desenvolvimento dos professores e outros profissionais envolvidos. Consideram que aprendem muito ao longo dos anos mas com a sua experiência enquanto professor.

Analisar os efeitos da formação contínua efectivamente frequentada nas representações e práticas dos professores: os efeitos são negativos já que não existem formação continuada mas sim seminários de refrescamento que muitas vezes não ajudam na superação das dificuldades dos professores. As formações não contribuem de modo algum para o desenvolvimento da sua prática diária pois não existe formações contínuas organizadas pelas instituições.

Compreender as implicações da formação contínua frequentada ao nível do desenvolvimento profissional dos professores e da(s) sua(s) identidade(s) profissional(ais): os professores auferem salários muito baixos com uma carga de trabalho muito elevada. Há professores que trabalham das 8 as 16 horas sem subsídios de alimentação e transporte.

Promover a formação em serviço dos jovens professores a leccionar nos colégios seleccionados para o estudo: as instituições do ensino privado estão apenas preocupadas com os lucros que possam tirar dali pois a maior parte dos donos das instituições na são formados na área e seus directores são funcionários públicos e vêm o ensino como uma forma de lucrar algum valor.

Analisar e interpretar o acompanhamento pedagógico dos professores das instituições seleccionadas: consideram que as direcções pedagógicas não têm capacidade para a exercer a actividade pois muitos deles não são formados na área. Os subdirectores pedagógicos apenas controlam a entrada e saída dos professores sem se importar com o trabalho realizado dentro da sala de aula. Os sub-directores pedagógicos consideram que o facto de analisarem os planos de aula é o suficiente para controlar o que se faz na sala de aula. 
Conhecer a importância dada pelas direcções dos Colégios à formação contínua dos seus professores: as direcções dos colégios não dão nenhuma importância as formações contínuas pois consideram mais um gasto para instituição. As direcções dos colégios não vem a formações como um investimento mais sim como um custo adicional na persecução dos seus objectivos de educação empresariais ou de produção.

Aferir o tipo e os critérios de avaliação da formação promovidos por estas instituições: Não existem critérios de avaliação das formações.

\section{REFERÊNCIAS}

Bisquerra, R. (1989). Métodos de investigación educativa: Guía práctica. Barcelona: CEAC.

Capistrán, R.W. (2018). Necesidades de formación docente de los maestros de Educación Artística a nivel Secundaria del Instituto de Educación de Aguascalientes. Artseduca, 19, 10-31. doi: 10.6035/Artseduca.2018.19.1

Flick, U. (2004). Introducción a la investigación cualitativa. Madrid: Morata.

Fox, D. (1987). El proceso de investigación en educación. Pamplona: EUNSA.

García, Z., \& Aznar, I. (2017). La formación de educadores infantiles, un reto de innovación educativa en la educación superior. Innoeduca. International Journal of Technology and Educational Innovation, 3(2), 98-108. doi: 10.24310/innoeduca.2017.v3i2.2451

González, M.T., \& Cutanda, M.T. (2017). La formación continuada del profesorado de enseñanza obligatoria: incidencia en la práctica docente y el aprendizaje de los estudiantes. Profesorado. Revista de currículum y formación del profesorado, 21(2), 103-122.

Gracia, L. (2017). Desenvolvimento profissional e carreira docente: diálogos sobre professores iniciantes. Acta Scientiarum. Education, 39(1), 79-89. doi: 10.4025/actascieduc.v39i1.29143

Hinojo, F.J., Cáceres, M.P., \& Raso, F. (2013). Análisis de los Componentes Organizativos de Centros de Formación Profesional en España. Revista Latinoamericana de Ciencias Sociales, Niñez y Juventud, 11(2), 783-801.

Joana, M., Sola, T., \& Aznar, I. (2014). Estudo das metodologias e estratégias do Programa de Português dos Cursos Profissionais de nível secundário: o caso do concelho de Almada. REICE. Revista Electrónica Iberoamericana sobre Calidad, Eficacia y Cambio en Educación, 12(2), 29-41.

Lessard-Hébert, M., Goyette, G., \& Boutin, G. (2005). Investigação Qualitativa: Fundamentos e Práticas. Lisboa: Instituto Piaget.

Marconi, M.A., \& Lakatos, E.M. (2010). Técnicas de pesquisa. São Paulo: Editora Atlas.

Martins, G.A., \& Lintz, A. (2000). Guia para elaboração de monografias e trabalhos de conclusão de curso. São Paulo: Editora Atlas.

Moisés, J.V., Aznar, I., \& Agreda, M. (2017). Liderança na Gestão Pedagógica: uma visão dos Directores das Escolas Secundárias. Journal for Educators, Teachers and Trainers, 8(1). 74-90.

Raso, F., Sola, T., \& Hinojo, F.J. (2017). Satisfacción del profesorado de la escuela rural de la provincia de
Granada (España) respecto a la organización escolar. Bordón. Revista de pedagogía, 69(2), 79-96.

Rodríguez, M.V., \& Hinojo, F.J. (2017). Incidencia de los Programas de Formación Pedagógica en el Perfil de los Profesionales No Licenciados en la Facultad de Educación de UNIMINUTO. Formación Universitaria, 10(5), 17-28. doi: 10.4067/S0718-50062017000500003

Yin, R. (2005). Estudo de Caso. Planejamento e Métodos. Porto Alegre: Bookman. 